\section{Reply: Still Squinting}

\section{Harlan B. Miller \\ Virginia Tech}

I' $m$ afraid this isn't a very entertaining literary controversy. Prof. Rollin replies gently to my criticisms, and I'm unable to find any grounds on which to denounce him.

Our differences are two. One is deep and complex. He's a meliorist and I'm an abolitionist. That's not the focus of this exchange. The second difference, of much less inherent importance, is whether one Rollin or two wrote Farm Animal Welfare.

Prof. Rollin usefully contrasts Socratic and Hegelian approaches to moral reform. The Socratic relies on 'reminding', on drawing out the consequences of what is already believed. The personality I called BER-MP proceeds Socratically, arguing that much contemporary treatment of nonhuman animals is unacceptable on principles already accepted by everyone but a few neoCartesian philosophers. (Many other writers also proceed in this way, of course.)

The personality I called BER-AT, on the other hand, proceeds in the Hegelian mode, "bringing to articulated awareness current movements in social thought." This mode is especially useful in freeing those protected from the Socratic approach by the armor of ideology.

Prof. Rollin denies that BER-MP and BER-AT are different actors. There's just one Bernard E. Rollin, operating in both Socratic and Hegelian modes. I'm still unconvinced, because in the passages I identify with BER-AT it seems to me that the relevant "current movement in social thought" is not being brought to awareness from the inside, but described from the outside. And that description often seems to me quite

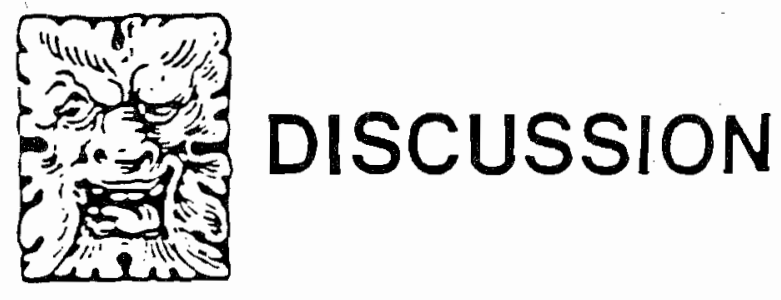

unsympathetic, sometimes hostile. BER-AT, as I read him, sees the new social ethic as an unfortunate reality with which agribusiness must deal (hence the flooding analogy) not as a positive transformation.

Maybe I'm being paranoid. Maybe I'm squinting too closely at the text. Read the book to find out. But read the book.

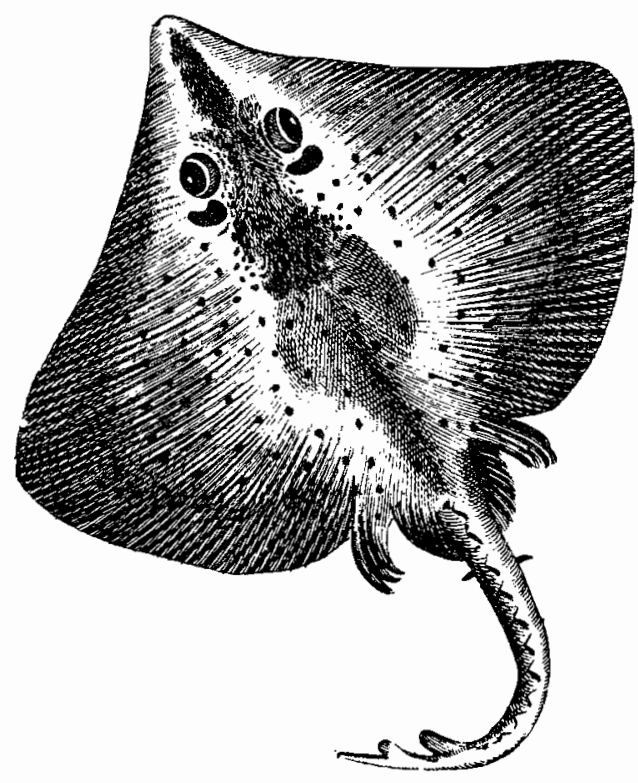

